\title{
ETAPAS EN LA CONSTRUCCION DE LA IGLESIA DE CAÑETE LA REAL
}

\author{
ROSARIO CAMACHO MARTINEZ
}

Cañete la Real, situada a $105 \mathrm{~km}$., de Málaga, casi en el límite con la provincia de Sevilla fue uno de los pueblos traspasados de ésta a la de Málaga en 1833 al estructurar la división regional, sin embargo su incorporación a esta diócesis fue más tardía pues hasta el decreto de la Sagrada Congregación Consistorial de 30 de abril de 1958 (1) no se ajustaron los límites del obispado a la división regional, formando este grupo de pueblos, situados entre Antequera y Ronda, el arciprestazgo de Campillos que agrupó además de Cañete, Almargen, Teba, Ardales, Campillos, Sierra de Yeguas y Peñarrubia (2).

Lógicamente la arquitectura que vamos a encontrar en esta zona poco tiene que ver con la de Málaga, es netamente sevillana y dirigida por maestros de aquella escuela y aunque a veces encontramos trabajando aquí a maestros locales y sobre todo de Antequera que dada su enorme actividad constructiva por estos años debía importar y/o exportar un buen número de profesionales, actúan siempre bajo las órdenes de aquéllos o de los directores de las obras.

La parroquia de S. Sebastián de Cañete la Real es obra noble e interesante por sus caracteres formales, pero además porque en ella intervienen una serie de maestros señeros de la escuela sevillana. Situada en un bivio del regular trazado urbano de Cañete, que surgió por traslado del primitivo poblamiento romano de la zona alta, evidenciando en esa regularidad extraordinaria una voluntad de asentamiento programado (3) cumple hoy una función urbanística constituyendo su fachada un punto focal de una de las principales vías de la estructura de la ciudad, pero al contrario que el pueblo la parroquia responde a una sucesión de etapas en su construcción.

Desconocemos la fecha de su erección pero en 1526 ya existía siendo su titular S. Sebastián (4). Tenía planta basilical de tres naves y estaba bien dotada, para ella el que fue maestro mayor de la catedral de Málaga, Pedro Díaz de Palacios, siéndolo anteriormente de la de Sevilla, en 1586 dió la traza para un monumento que Juan Bautista Vázquez, Juan de Oviedo como fiador y Jerónimo Hernández se comprometían a hacer (5); también contaba con un coro y buen órgano que en octubre de 1716 , al ser derribada la parroquia, fue desmontado y trasladado por el maestro de órganos de Málaga Antonio Morodo (6).

(1) Dato facilitado por D. Juan Ortega, canciller del obispado de Málaga.

(2) Alameda tambièn estaba incluida en este grupo sevillano, pero por su situación se incorporó al arciprestazgo de Antequera.

(3) MORENO PERALTA, S.: Actuaciones en centro histórico particularizado a Málaga. Conferencia pronunciada en el Colegio de Arquitectos de Málaga $22-$
-1980.

(4) LOPEZ, T.: Diccionario geográfico de Espanta. Vol.: Málaga-Granada m/5. n. 7303 de la Biblioteca Nacional $\mathrm{f}^{\circ} 54$.

(5) LOPEZ MARTINEZ, C.: Desde Jerónimo Hernández a Martínez Montantéz. Pág. 120. Vid.: Archivo Temboury

(6) A.G.A.S. Leg. $258 \mathrm{I}_{\mathrm{B}}$ pieza 2 fol. 11 . 
Efectivamente, en 1715 la parroquia se encontraba en estado ruinoso, informando la fábrica que la techumbre se estaba hundiendo viendo conveniente acabarla de derribar y hacerla de nuevo y solicitaba la presencia del maestro mayor de fábricas del arzobispado para su reconocimiento; lo era entonces Diego Antonio Díaz (7) quien, en informe fechado en agosto de 1715, indicó, después de reconocer la iglesia, era mejor demolerla e invertir el dinero de la reparación y los materiales en una iglesia nueva, que parece se había empezado sin la oportuna licencia, pues el Cabildo sólo tuvo noticia de ella a través de este informe.

Sin embargo, a juicio de la Diputación de Negocios, que llevaba a su cargo las obras del arzobispado, el maestro se había excedido en su cometido al informar sobre la conveniencia de continuar la nueva iglesia de la cual sólo faltaban trece varas correspondientes a los dos últimos intercolumnarios, zona que estaba incluso sin cimentar (8).

A pesar de ello el provisor del arzobispado dio licencia para demoler y proseguir "la obra de la iglesia nueva que está comenzada", aplicándole diferentes rentas: $5.600 \mathrm{r}$. del alcance del mayordomo anterior, el sobrante anual de la renta de la iglesia una vez deducido el importe de las obligaciones ordinarias y extraordinarias y la cuarta parte de los diezmos (9). Sin embargo en cabildo del 19 de agosto se instó a la Diputación para que el provisor se opusiera a dicha obra y se solicitó el reconocimiento de otros maestros (10).

Estos fueron Cristóbal Portillo de Abilla y Lorenzo Fernández Iglesias que, junto con Diego Antonio Díaz, el 3 de junio de 1716 declararon ante notario que habían reconocido ambas iglesias remitiéndose Díaz a su informe anterior y los otros afirmaron no valía la pena arreglar la parroquia vieja que siempre quedaría imperfecta por afluir las aguas a una canal maestra que estaba entre las dos iglesias y disponerse la nueva en posición contraria a la vieja, insistiendo en continuar la iglesia nueva. Describen la obra hecha que se encontraba incluso enlucida y tejada y era la que servía a los vecinos pero resultaba aún pequeña, por ello los maestros se ratifican en la conveniencia de continuar los tramos que faltaban, que aprovechando los materiales del derribo de la iglesia vieja no excedería en mucho la cantidad calculada por Diego Antonio Díaz en su informe anterior (11).

El 21 de octubre de 1716 comenzó el derribo realizando este trabajo el maestro de Cañete Alonso Domínguez y el 2 de diciembre de 1717 empezaron a abrirse las zanjas para los cimientos de la obra nueva por orden del maestro Díaz; ésta recayó en el maestro albañil de Sevilla Silvestre Tirado colaborando el oficial José de Usarraga. Durante 1718 Lorenzo Fernández Iglesias, maestro mayor de cantería dirigió la labor de cortar los cantos de piedra, trazarlos y labrarlos, con siete oficiales venidos de Morón, Ronda y Teba; en 1720 trabajó otro maestro de cantería Tomás Ignacio García de Paredes con dos oficiales de Antequera (12). La presencia de estos maestros demuestra que en estos años estaban realizándose las fachadas, obras magníficas de cantería y se arrastrarían hasta 1740 como indica la fecha tallada en la portada principal.

A finales de 1725 debió haber ciertas irregularidades, pues el maestro de obras de Sevilla Francisco Díaz fue enviado a Cañete por "orden de los señores de la Diputación secretamente a

(7) SANCHO CORBACHO, A.: Arquiteclura barroca sevillana del s. XVIII pág. 143.

(8) A.C.S. Diputación de Negocios. Libro 332 (27) antiguo 8 fol. $143 \mathrm{v}-144 \mathrm{v}$.

(9) A.G.A.S. Leg. $2581_{\text {B }}$ pieza 2 fol. 8 y v.

(10) A.C.S. Dipulación de Negocios. Libro 332 (27) antiguo 8 fol. 145

(11) A.G.A.S. Leg. $2581_{\text {B }}$ pieza 2 fol. 18-19.

(12) A.G.A.S. Leg. $258 \mathrm{l}_{\mathrm{B}}$ pieza 2 fol. $22-32$. 
continuar la obra de la nueva iglesia"', trabajando con él el oficial de Sevilla Juan Pizarro, junto con Francisco Miranda de Cañete (13).

Unos años más tarde, en 1764 , se solicitaron obras de reforma para esta iglesia nueva. El provisor, por petición de la fábrica de Cañete solicitó de la Diputación de Negocios reparaciones en la torre y la armadura que fueron reconocidas por Ambrosio de Figueroa, maestro mayor de fábricas, declarando era preciso derribar el remate de la torre y hacerla más alta pues estaba más baja que la armadura y esto le causaba notable perjuicio tasando la obra en 12.000 reales de vellón; en cuanto a la armadura informó era preciso desmontarla y reedificarla, obra costosa que ascendería, en un cálculo aproximado, a 21.965 reales. Fue aprobada la obra que sería costeada secuestrando la cuarta parte del pan y maravedíes (14).

Sin embargo parece que no se acometió, o al menos no se terminó, hasta 1767 pues en un informe de Pedro de Silva de abril de 1778, con motivo de unas reparaciones necesarias en los tejados y sacristía dice "en el año pasado de mil setecientos sesenta y siete, si el declarante no se engaña, se hizo una gran obra en esta iglesia y en la sacristía, que lo principal de la nominada consistió en tejar de nuevo todos sus tejados, con su sacristía y en la torre también se hizo una gran reparación, como en todo lo demás que por entonces necesitó la citada iglesia, cuya obra la proyectó y visitó el declarante y la ejecutó Antonio de Figueroa, que hoy es también maestro mayor de fábricas y fue su director D. Vicente de Gálvez, vecino de la mencionada villa" (15). En esta visita de 1778 Silva solicitó que el informe y aprecio lo hiciera Antonio de Figueroa, por ser quién la ejecutó y que se encontraba cerca trabajando en la iglesia de Algodonales. Presentó éste su informe sobre la reparación de los tejados, sacristía y pretiles del porche, que tasó en 7.866 (16) y el Cabildo acordó que la obra fuese costeada con las rentas de diezmos (17).

Poco tiempo después la iglesia era de nuevo insuficiente para las necesidades de la población, recibiendo a finales del siglo una considerable ampliación consistente en la adición de un crucero y capilla mayor y otras dependencias y fue proyectada la obra por Antonio de Figueroa. En su informe, firmado el 6 de junio de 1791, alude a las dificultades del proyecto ya que por el lado de la nave del Evangelio el terreno era 7 varas inferior al pavimento de la iglesia y 2 por el lado de la Epístola proyectado además de la dicha capilla un cuarto para el tesoro de la iglesia y otro encima para guardar el monumento y un panteón subterráneo para 42 nichos, además de otros servicios, siendo necesario sacar los fundamentos de cantería, la capilla en su interior debía cubrirse con bóveda vaída o por aristas; se tasó èsta ampliación en 63.483 reales (18). Debían existir dos planos realizados por el maestro pues a ellos se alude en una factura firmada por José Francés, proveedor de la obra (19).

El mayordomo de la fábrica de la iglesia comunicó en enero de 1793 se había empezado la obra que fue tasada por un alarife de la villa en 38.000 reales ofreciendo pagarla de los bienes y rentas de la fábrica, pero habiendo una gran diferencia con la tasación realizada por Antonio de Figueroa pidió al provisor del arzobispado que de las cuartas partes se aportasen 20.000 reales (20); al mes siguiente el maestro alarife de Cañete Juan Hidalgo midió la iglesia, por orden del

(13) A.G.A.S. Leg. $258{ }^{1}$ B pieza 2 fol. 80 y ss.

(14) A.C.S. Diputación de Negocios. Libro 337 (32) (antiguo 12) fol. 33 - 34

(15) A.G.A.S. Leg. 2582 p pieza 2 fols. $2-3 v$.

(16) A.G.A.S. Leg. 2582 pieza 2 fols. $9-12$

(17) A.C.S. Diputación de Negocios. Libro 337 (32) (antiguo 12) fols. 309y - 310

(18) A.G.A.S. Leg. 2321 fols. 12-13v.

(19) A.G.A.S. Legl. 2321 fol. 217.

(20) A.G.A.S. Leg. 232 fol. $37-38 v$. 
vicario, que resultó de 524 varas cuadradas, siendo este maestro quién llevó a cabo la obra como consta en las cuentas de la fábrica (21).

En enero de 1795 Fernando Rosales, maestro mayor de obras de fábricas de Sevilla (22), después de reconocer la capilla mayor e informado sobre ella hizo presupuesto de la solería, una vivienda para el sacristán y camposanto anejo, con lo cual se ampliaba la obra iniciada en 1793 (23); en mayo, al solicitar el arreglo de la solería se pidió también la construcción del nuevo cementerio (24). Aún no se habían terminado las obras en 1796, pero en agosto de ese año una nueva declaración del maestro mayor afirmaba que se había concluído la cabecera hasta la solería, retablo y escaleras del camarín, resanado y blanqueado la media naranja con sus torales y cubierto la sacristía, construyéndose también su cañón interior y estaba próximo a concluirse el osario. La cantidad invertida fue de 158.000 reales y las escasas obras que faltaban ascendían tan sólo a 36.400 reales (25). El 27 de mayo de 1797 declaró que la iglesia estaba terminada y había sido construída con arreglo a lo establecido (26).

La parroquia tal como hoy se encuentra conserva las dimensiones citadas por los maestros en sus diferentes informes y responde a las sucesivas etapas en que fuera construida. Tiene tres amplias naves separadas por columnas toscanas de piedra a las que se superponen trozos de entablamento apoyando arcos de medio punto y pilastras que sostienen otro entablamento más reducido con ménsulas pareadas bajo la cornisa, de ella arranca la bóveda de medio cañón con lunetos, que cubre la nave central, alzada a la gran altura que permite el usar dos diferentes soportes superpuestos (Lám. I). Las naves laterales, delimitadas por fajones apoyados en pilastras o ménsulas se cubren con bóvedas de arista (Fig. 1).

El crucero está cubierto por bóveda semiesférica segmentada por ocho nervios, apoyada en pechinas con escudos, sus brazos presentan bóvedas vaídas recorridas por baquetones y en los puntos en que se cruzan se superponen rosetones de menuda decoración vegetal.

Tras un arco triunfal que toma forma avenerada hacia el interior se encuentra la capilla mayor, retangular, con bóveda de medio cañón surcada por lunetos muy amplios cuyas aristas limitan tornapuntas y pequeñas rocallas y apuntan a un medallón de igual decoración con la figura del Espíritu Santo, que armoniza con la que envuelve a los querubines en los lunetos. Al retablo mayor se abre, entre columnas salomónicas, un camarín semipoligonal de lados calados y amplias placas con decoración vegetal, roleos y querubines, cubierto con bóveda segmentada por seis nervios de perfil sinuoso que confluyen en una estrella central.

En la nave del Evangelio se alza una capilla camarín que hoy ocupa la Virgen de Caños Santos, patrona de la villa, y en la que se veneraba a la Virgen de la Aurora, obra de Duque Cornejo, que fue conducida desde Sevilla en 1740 , fecha en que se puede situar la construcción del camarín; ambas obras fueron realizadas a expensas de D. Juan de Figueroa Silva Lazo de la Vega, vecino de la villa (27). Tiene planta polilobulada con pilastras corintias cajeadas que descuel-

(21) A.G.A.S. Leg. 232 fols. 45 y 174

(22) Aunque desde 1783 era arquitecto diocesano, hasta febrero de 1795 no recibió el nombramiento definitivo para actuar como maestro mayor det arzobispado. SANCHO CORBACHO, A.: Op. cit., pág. 263.

(23) A.G.A.S. Leg. 2321 fols. 110-113.

(24) A.G.A.S. Leg. 2321 fols. 118-119. La construcción del cementerio para el que se pide que las Justicias sef̂alen el lugar adecuado estuvo motivada por una Real Orden que determinaba se sacasen de las parroquias los enterramientos y en Cantete era necesario un camposanto por tener un vecindario muy nutrido y eran insuficientes los enterramientos de la iglesia que mantenian una soleria deshecha y ambiente poco respirable.

(25) A.G.A.S. Leg. 2321 fols. $150-151$.

(26) A.G.A.S. Leg. 2321 fol. 171 y v, OJEDA, P.: Reseffa la más antigua que se conoce sobre la antiguedad de la villa de Cattete la Real, propio de D. Antonio Talavera Jiménez año 1894 . Su autor el P. Ojeda Vid.: Archivo Díaz de Escobar caja 105 ley 59 c.8. En esta resefa se sitúan las obras del crucero entre $1972-97$.
(27) LOPEZ, T.: Op. cit., fol. 54 y y. 
gan hojarasca y la cubre una bóveda de gajos con los símbolos marianos encerrados en medallones rodeados de ornamentación vegetal.

En el interior son claras las cuatro fases en que se construyó el templo. El cuerpo de naves responde a la primera etapa, anterior a 1715 , y frente a su alzado de columnas y pilares superpuestos evocamos la vecina parroquia de Teba, con un alzado semejante cuyo proyecto y construcción se deben a José Tirado, maestro mayor de Fábricas de Sevilla y su arzobispado (28). Dado que la iglesia de Cañete se construyó sin licencia no tenemos noticia documental del maestro que la trazó, pero debió tener presente la parroquia vecina que se construyó entre 1700 y 1715 o incluso intervenir o asesorar el propio José Tirado. De lo que no hay duda es que el tipo prospera pues a él responde la iglesia de S. Roque de Sevilla construída por Pedro de Silva en $1760(29)$.

Pero los dos últimos tramos de la parroquia de S. Sebastián pertenecen a la segunda fase, obra que ordenó Diego Antonio Díaz en 1717 y que llevó a cabo el maestro albañil de Sevilla Silvestre Tirado, sin embargo la presencia de las ménsulas-dentículo que corren bajo la cornisa, elemento muy querido por Díaz que los utilizó en Umbrete y con ritmo pareado, como aquí, en la Santísima Trinidad de Carmona, pueden indicar que además del proyecto de los últimos tramos se aportarían nuevos elementos en el alzado general de la iglesia.

La tercera etapa no afectó externamente al interior pues se reduce a la restauración de las armaduras, en cambio la cuarta, proyectada en 1791 por Antonio de Figueroa, cambió totalmente el aspecto de la iglesia al añadírsele el crucero, capilla mayor y camarín, además de otras dependencias; los elementos decorativos de esta zona entroncan con el estilo de Figueroa, clarísimos en el camarín con sus nervios formados por placas superpuestas, las formas estrelladas y los óculos.

En el exterior se combinan la piedra como aparejo de mampostería en los muros laterales, sillería en ángulos y enmarcando la portada principal y labrada en las portadas, con el ladrillo, material por excelencia de esta obra, que alterna con la mampostería por hiladas y resalta en la fachada y torre.

La fachada principal queda encajada entre dos contrafuertes que limitan la anchura de la nave central y sobre ellos se levanta un frontón de ángulos en resalto coronados por bolas. La portada propiamente dicha está labrada en piedra, y se abre en arco de medio punto, sobre pilastras cajeadas, cuya rosca tiene placas con decoración vegetal, veneras y escudos y clave resaltada, en las enjutas acantos estilizados rodean unos medallones con la inscripción AÑ DE 1740; lo flanquean columnas dóricas acanaladas sosteniendo entablamento del mismo orden sobre el que se alzan los extremos de un frontón coronados por flameros abalaustrados. La línea del entablemento se quiebra hacia arriba, conservando sólo de una más austera decoración un triglifo que marca el eje quedando el resto convertido en una moldura vegetal que enmarca un recuadro con una gran placa con escudo rodeado de acantos.

Sobre este cuerpo y marcando la transición con ligeros tornapuntas, se alza un ático con hornacina avenerada que cobija la imágen del titular, flanqueada por pilastras dóricas cajeadas con pendientes vegetales y pedestales con placas romboidales; el entablamento, dórico, sustituye los 
triglifos y metopas centrales por decoración floral dejando caer sobre la clave del nicho una macolla con querubín, sobre él dos recias volutas soportando pares de pináculos flanquean escudo pontificio coronado (Lám. II). Un óculo abocinado sirve de unión con la base del frontón de coronamiento en la cual hay una inscripción: ADORATE DOMINUN IN ATRIO SANCTO ET JUSTO. La fachada se amplia lateralmente, abarcando la anchura de las tres naves apareciendo ménsulas bajo la cornisa, motivo que recorre todo el edificio.

Las portadas laterales, también labradas en piedra, resaltan sobre el muro encalado y se abren con arco de medio punto, sobre pilastras cajeadas, flanqueado por otras dóricas que sostienen entablamento del mismo orden con el anagrama de María, inscripciones y símbolos marianos; apoya un frontón curvo enrollado flanqueando una repisa central coronada por cruz, motivo que se repite en las curvas laterales (Lám. III).

En la cabecera, de mampostería con hiladas de ladrillo y cadenas de sillares en los ángulos destaca el volumen del camerín colgado sobre la calle.

La torre, de ladrillo y muy airosa, se alza sobre un basamento de piedra y en los dos cuerpos inferiores, cuadrados, la decoración corre de uno a otro atravesando la línea de imposta reduciéndose a un apilastrado superpuesto cobijando placas y vanos macizados adintelados o arqueados, cortándolo una cornisa rematada por pretil con incisiones romboidales y pináculos de piedra entre los que emerge el cuerpo de campanas que responde a un tratamiento mucho más rico. Se abre con vanos de medio punto flanqueados por pilastras y toma forma octogonal disponiendo los ángulos en chaflán sobre los que cae una pilastra almohadillada sobre placa recortada. Tras un ático recorrido por bulbosos pináculos surge el chapitel, piramidal de caras rectas, en el que con la cerámica vidriada se diseña un atractivo zig - zag. (Lám. IV).

Respecto al proceso de las obras, las portadas debieron realizarse en la fase segunda arrastrándose hasta 1740; ya desde 1718 el maestro de cantería Lorenzo Fernández Iglesias estaba dirigiendo la labor de cortar la piedra, viniendo más tarde el también cantero Tomás Ignacio García de Paredes; podría pensarse en una intervención de estos maestros en el diseño de los exteriores, sobre todo comparando con la portada del palacio arzobispal de Sevilla, obra de Iglesias, con su esquema estilizado y la menuda decoración, pero la presencia del orden dórico al exterior como en S. Pedro de Arcos de la Frontera e incluso el tratamiento de la decoración que guarda relación con obras jerezanas en las que se apunta la intervención de Díaz (30) nos hace pensar que se mantendría el diseño que como maestro mayor de las fábricas del arzobispado y de la catedral daría éste, tanto para el interior como el exterior, perteneciendo a este proyecto también los cuerpos inferiores de la torre.

En cuanto al cuerpo de campanas, que no sobrepasaba la altura de las cubiertas, se deshizo tras el informe de 1764 del maestro mayor de fábricas Ambrosio de Figueroa haciéndolo de nuevo en 1767 Antonio de Figueroa, sin embargo el proyecto no es de ninguno de estos maestros. En un informe de 1778, el también maestro mayor de obras del arzobispado Pedro de Silva, refiriéndose a esta obra deja claro que el diseño le pertenece siendo el ejecutor Antonio de Figueroa.

El uso del chapitel piramidal alargado de caras rectas es un elemento típico de este último que lo empleó en la Palma, Bollullos y otras iglesias realizadas por él, desde luego en fecha muy 
posterior a ésta, aunque también es cierto que Diego Antonio Díaz inició ya esta forma y Silva lo empleó en S. Roque de Sevilla (31) aunque ambos concedían más importancia al banco reduciendo el cuerpo piramidal a simple remate. Lo cierto es que al parecer este chapitel aquí en fecha tan temprana se sitúa esta obra como una de las primeras en las que toma cuerpo este elemento tan característico de la etapa final del s. XVIII en Sevilla.

En la cuarta etapa de la construcción el exterior se transformó notablemente con la adición del crucero y capilla mayor, pero estos cambios afectaron al volumen general del templo y salvo la espadaña no hay ningún elemento que destacar.

Así pues en Cañete la Real, tan olvidado en el límite entre las dos provincias y muy mermada la importancia que alcanzó en siglos pasados, encontramos una iglesia que nos ofrece un conjunto de experiencias de algunos de los más grandes maestros sevillanos del siglo XVIII y el crisol donde fraguaron algunas formas características de esta escuela.

\section{FUENTES}

A.C.S. (Archivo de la Catedral de Sevilla) 'Diputación de Negocios' Libro 332 (27), 337 (32).

A.G.A.S. (Archivo General del Arzobispo de Sevilla) Leg. $2581_{B}, 2582_{B}, 2321$.

A.D.E. (Archivo Díaz de Escovar) Caja n. ${ }^{\circ} 105$, Leg. 58 c. 8.

BIBLIOTECA NACIONAL m/s. ${ }^{\circ}{ }^{\circ} 54$ LOPEZ, T.: Diccionario geográfico de España. Vol. Málaga-Granada. 


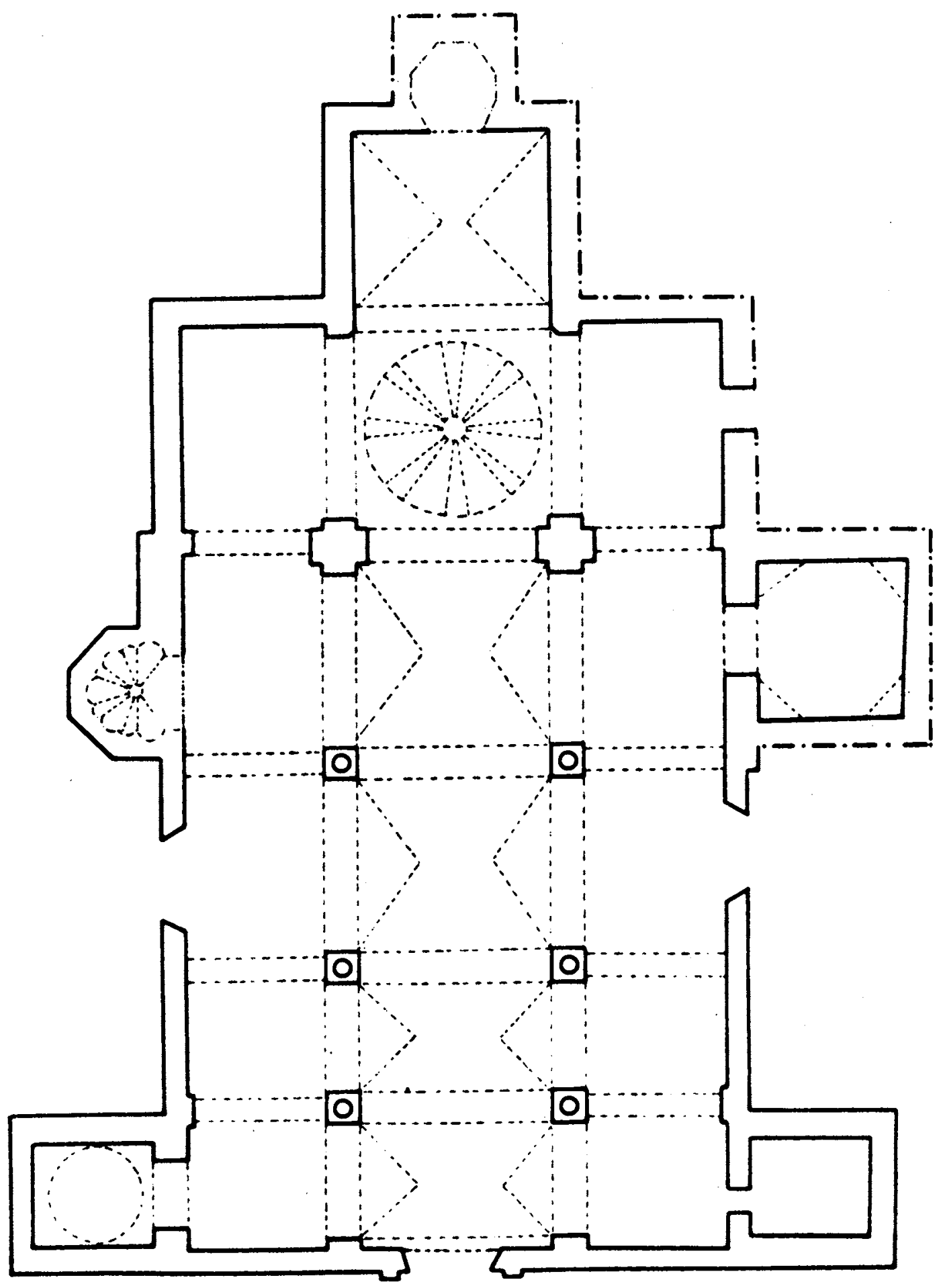

0

PARROQUIA DE SAN SEBASTIAN. 


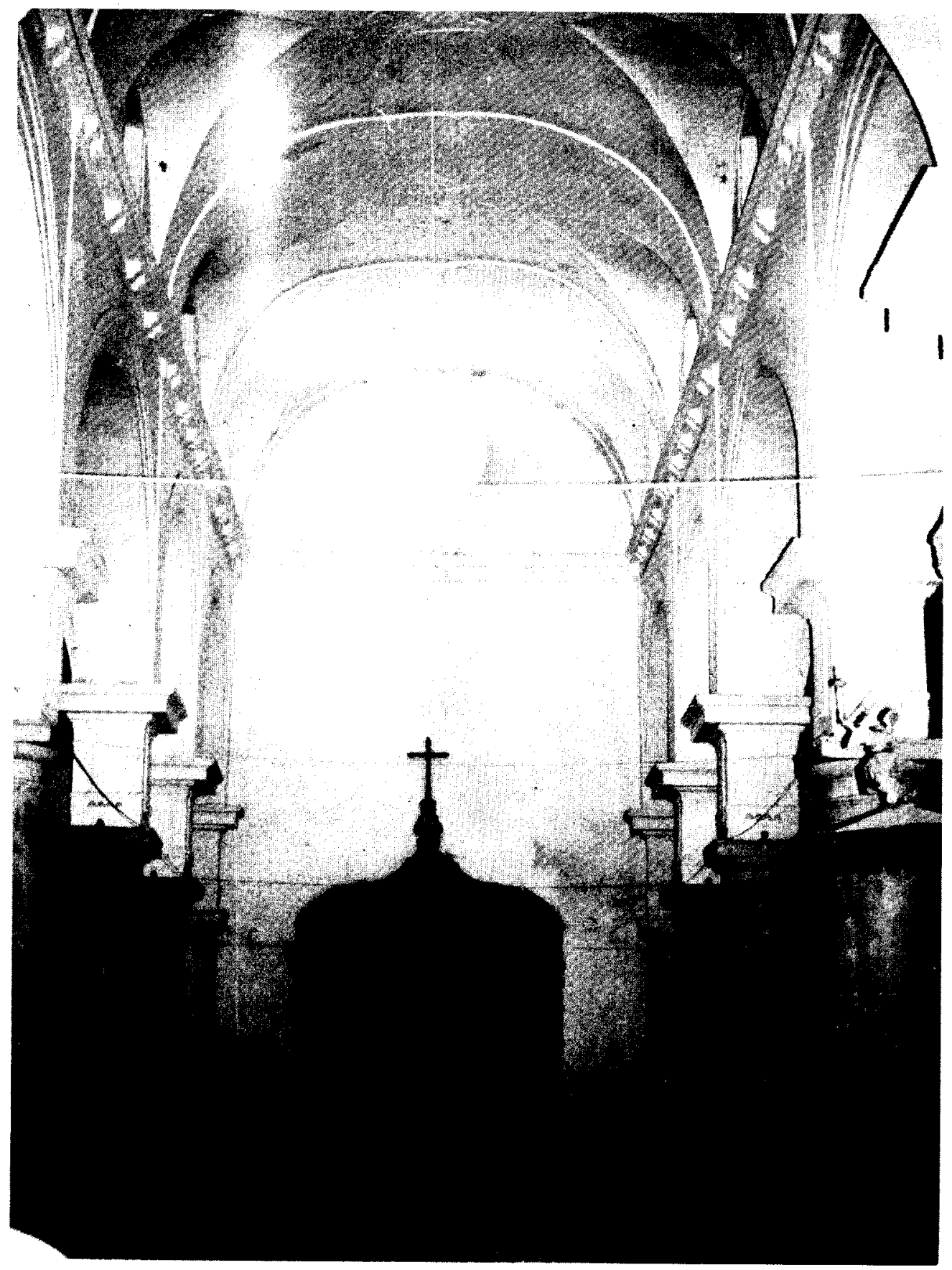

LAMINA I

Cañete la Real. Parroquia de S. Sebastián 


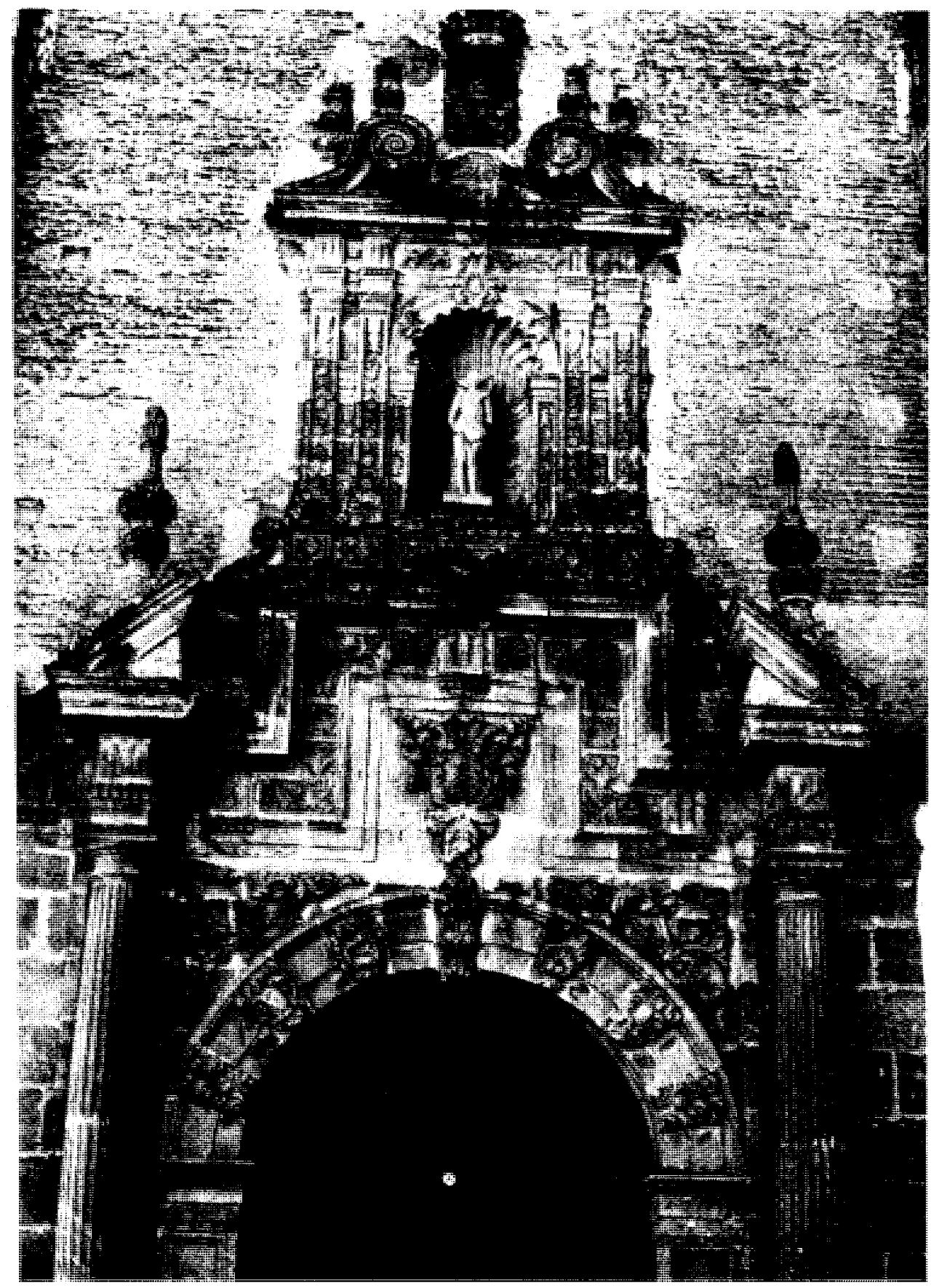

LAMINA II

Cañete la Real. Parroquia de S. Sebastián. Portada principal 


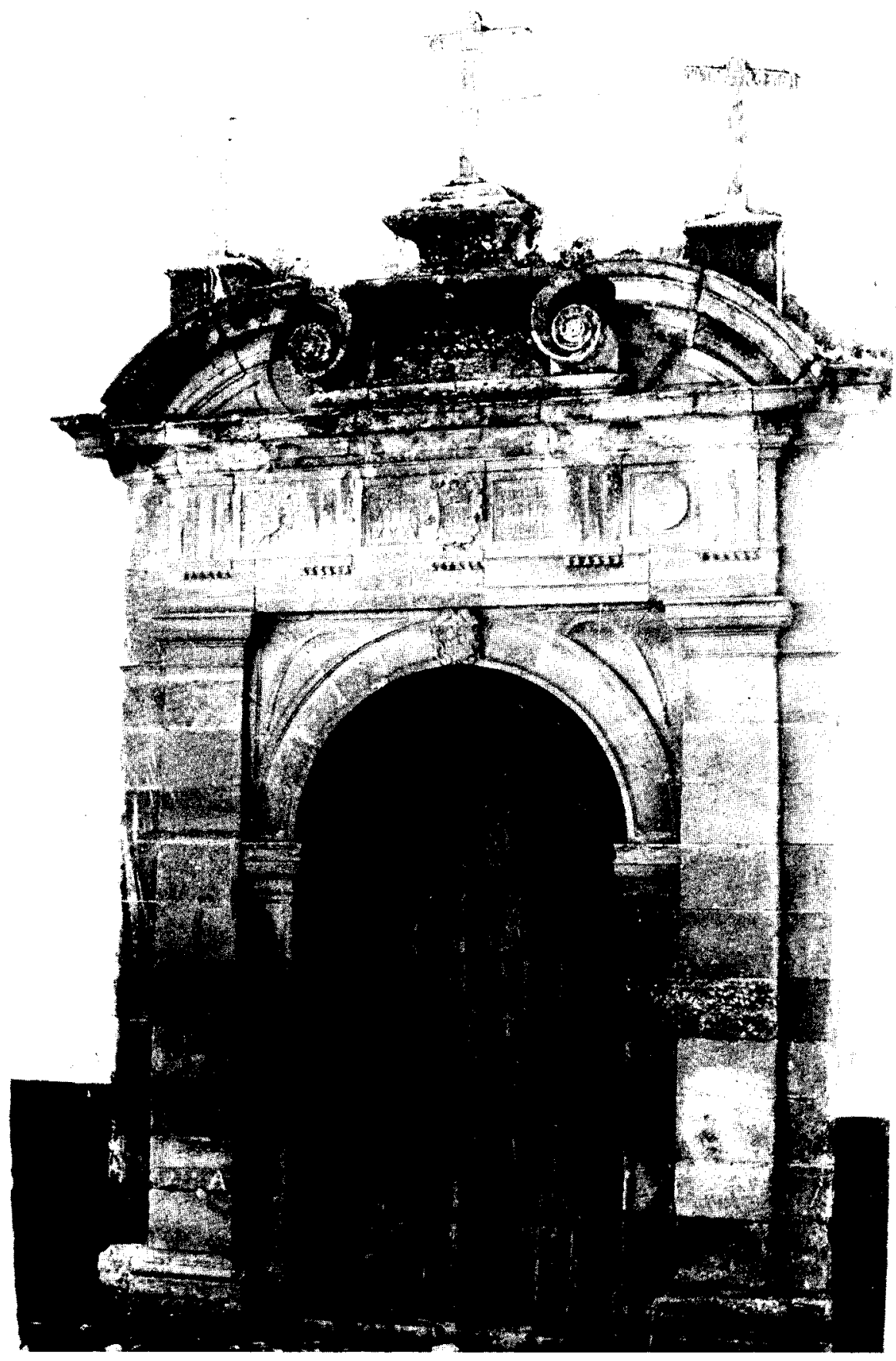

LAMINA III

Cañete la Real. Parroquia de S. Sebastián. Portada lateral 


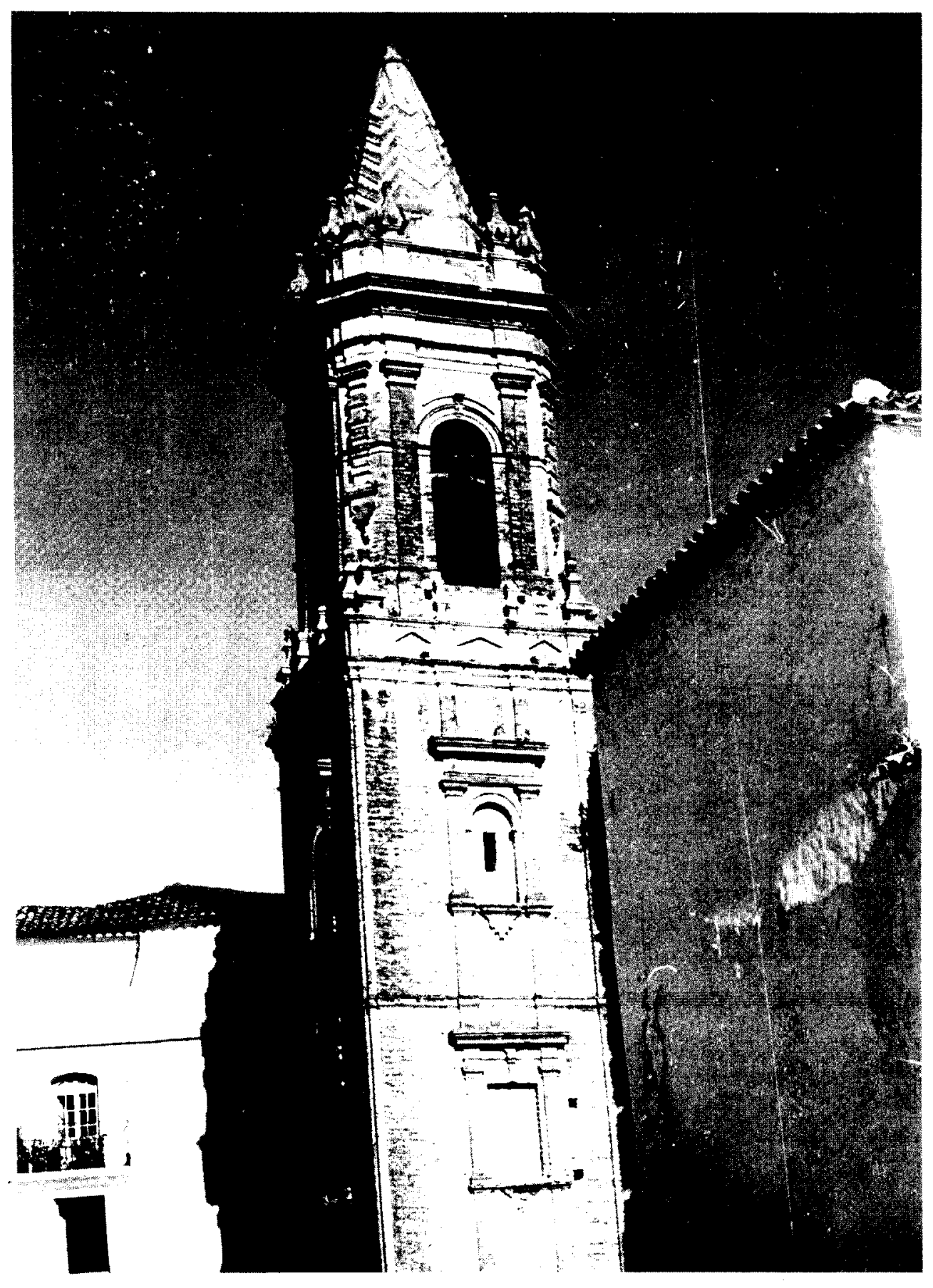

LAMINA IV

Cañete la Real. Parroquia de S. Sebastián. Torre 